\title{
PRIMARY PREVENTION OF CHRONIC DISEASES IN ADOLESCENCE: EFFECTS OF THE MIDWESTERN PREVENTION PROJECT ON TOBACCO USE
}

\author{
MARY ANN PENTZ,' DAVID P. MACKINNON,' BRIAN R. FLAY, \\ WILLIAM B. HANSEN,' C. ANDERSON JOHNSON ${ }^{1}$ AND JAMES H. DWYER'
}

Pentz, M. A. (Dept. of Preventive Medicine, U. of Southern California, Pasadena, CA 91101), D. P. MacKinnon, B. R. Flay, W. B. Hansen, C. A. Johnson, and J. H. Dwyer. Primary prevention of chronic diseases in adolescence: effects of the Midwestern Prevention Project on tobacco use. Am J Epidemiol 1989;130:71324.

This article reports six-month, one-year, and two-year effects of a longitudinal multicomponent community program directed toward delaying the onset of cigarette smoking in adolescence. Results are based on a longitudinal panel of sixth and seventh grade students from eight schools in the Kansas City Standard Metropolitan Statistical Area $(n=1,122)$. In the fall of 1984, schools were assigned to either a program group, which received school, booster, parent, and mass media program components, or a control group that received regular health education programming in school and mass media exposure. By six months, there was a significant effect of the program on recent smoking, with the prevalence of smokers in the program group increasing more slowly than in the control group. At two years, $19 \%$ of students in the program group reported smoking in the last month versus $29 \%$ of students in the control group; and $12 \%$ versus $19 \%$, respectively, reported smoking in the last week. The lifetime prevalence rate showed a marginal program effect at two years, with $57 \%$ of students in the program group having smoked once or more compared with $65 \%$ in the control group. The program was also effective across different levels of cigarette use ranging from no current use to use of one pack or more per day at two years.

adolescence; chronic disease; drug utilization; health education; health services; smoking

Nearly one third of all premature deaths in the United States are attributable to the abuse of addictive substances, most prominently tobacco and alcohol (1-3). Cigarette smoking alone is the single most prevent- able behavioral factor in illness, disability, and death, despite widespread knowledge of its harmful effects $(4,5)$. Most at risk for adoption of cigarette smoking, alcohol drinking, and other drug use are young
Received for publication July 31,1987 , and in final form April 11, 1989.

${ }^{1}$ Institute for Health Promotion and Disease Prevention Research, Department of Preventive Medicine, University of Southern California School of Medicine, Pasadena, CA.

${ }^{2}$ Prevention Research Center, School of Public Health, University of Illinois at Chicago, Chicago, IL. Reprint requests to Dr. Mary Ann Pentz, Institute for Health Promotion and Disease Prevention Research, Department of Preventive Medicine, Univer- sity of Southern California, 35 North Lake Avenue, Suite 200, Pasadena, CA 91101.

This study was supported by Grant DA03976 from the National Institute on Drug Abuse to the first author and four coinvestigators and grants from the Ewing Marion Kauffman Foundation and the Lilly Endowment, Inc.

The authors thank Drs. Tom Cook, Lloyd John. ston, and Calvin Cormack for their helpful comments and Martha Petrov and Anntoinella Wilkie for assistance with manuscript preparation. 
adolescents $(6,7)$. This period of development, beginning approximately in the year of transition to middle school or junior high school and extending through the first year of high school (ages 10-14 years), has been associated with a fivefold increase in cigarette smoking (5). School transition has been suggested as a critical risk period for smoking and other problem behavior in youth $(7,8)$.

The majority of large-scale smoking prevention programs have been school-based and have been implemented in or included implementation in the seventh grade, regardless of whether that grade represents a school transition year (8-12). Most programs have been shown to produce changes in knowledge and attitudes but little change in smoking behavior $(10,12)$. Programs that do show effects on behavior tend to focus on resisting social influences to smoke, teaching youth how to resist pressures to smoke, and promoting social norms for nonuse through peer modeling of nonuse and, in some cases, practice in broader competence skills such as assertiveness (5, $9,11,12$ ). While there are some exceptions, such as the effects reported on smoking incidence from a national health education program focusing on physical influences (School Health Curriculum Project (13)), a meta-analysis of school-based prevention studies indicates that programs focusing on social influences produce consistent reductions in cigarette smoking onset compared with other more traditional educational programs or with control groups receiving no program (10).

Unfortunately, the capability of schoolbased social-influences programs to produce sustained population-wide changes in smoking or to prevent health-compromising lifestyles and ultimately chronic disease is yet to be demonstrated $(13,14)$. With few exceptions, such as the five-year evaluation of Minnesota smoking prevention programs on cumulative incidence rates (15), most studies have shown either immediate effects, with no effects after six months or one year, or no significant effects until one year or more after program im. plementation (12). Effects have been limited to delaying onset among nonusers rather than impacting on user groups or on population prevalence rates (16).

Several methodological problems may have contributed to these weak effects. One is that little attention has been given to environmental influences that could affect the validity and strength of a smoking prevention program. Recent research suggests that school transition, program boosters or refreshers, parents, and mass media influence adolescent smoking and should be addressed together in a comprehensive smoking prevention effort $(12,13,17)$. Other problems have included a failure to match units of analysis with units of experimental assignment (for example, analyzing data on individuals when school is the unit of assignment) and a failure to adjust for attrition and other potentially confounding factors in analysis where true random assignment of schools is not possible (for example, where participation in a prevention research project is voluntary or where schools differ in size, racial composition, or structure (18-20)). Some of these problems have been addressed in large multicommunity studies of heart disease prevention, which have shown some reductions in smoking among youth (e.g., 21, 22). However, they have typically not been addressed in large-scale studies of smoking or drug prevention.

This article reports six-month, one-year, and two-year results of intervention on a longitudinal panel of young adolescents who are evaluated each year as part of the Midwestern Prevention Project, a six-year multicomponent community program directed toward smoking and drug abuse prevention. The program focuses on resistance skills training and environmental support of nonsmoking and non-drug use norms through the use of school, booster, parent, and community organizations programs, health policy changes, and mass media programming. Intervention is initiated during the year marking the transition to middle scl
se
su
tre
tio
for
pr
scl
sis
de
es
ne

si
va
de
im
pe
tri
hi
Pi
sc
tit
pc
In
tis
a
sc
in
St
sc
sc
16
be
to
cc
Ic
ci
in
as
flt
to
tir
fr
pe


school or junior high school (the sixth or seventh grade) on the basis of research suggesting a modifying effect of school transition on smoking and smoking prevention (8). The results reported in this study focus on the effects of two years of the program on adolescent smoking, using both school and individual as the unit of analysis, with adjustments made for attrition and demographic differences that were hypothesized as confounders of program effectiveness.

\section{MATERIALS AND METHODS}

\section{Study design}

The Midwestern Prevention Project is a six-year longitudinal intervention study, varying treatment condition (program or delayed program control) by grade of initial implementation (grade six or seven), depending on which grade represents the transition year to middle school or junior high school. The Midwestern Prevention Project was initiated in all 50 middle schools/junior high schools and communities in the Kansas City Standard Metropolitan Statistical Area in 1984 and in the Indianapolis Standard Metropolitan Statistical Area in 1987. This study focuses on a longitudinal panel of youth from eight schools who have been tracked individually in the Kansas City Standard Metropolitan Statistical Area since 1987.

Experimental assignment of panel study schools occurred after school curriculum schedules had been developed for 19841985. Thus, assignment to conditions was based on each school administrator's ability to revise school program schedules to accommodate the prevention program in 1984-1985. Sixteen schools were sufficiently flexible to schedule the program for immediate implementation or be randomly assigned to control; 34 schools did not have flexibility and were subsequently assigned to either immediate program implementation $(n=15)$ or control $(n=19)$. Schools from each of these groups were matched by pairs for urbanicity (one program school and one control school from rural, suburban, suburban/urban, and inner-city urban areas). The eight panel schools were randomly selected from these pairs.

\section{Subjects}

Subjects were all sixth and seventh grade transition year students from eight schools who were evaluated in a baseline measurement in fall 1984. The sample was 50 percent male and 82 percent white, 14 percent black, and 4 percent other races. Forty-five percent of the sample was in the sixth grade (middle schools) and 55 percent was in the seventh grade (junior high schools), with a mean age of 12.8 years (range, 12-14 years); 47.7 percent reported having used cigarettes once or more in their lifetimes. These characteristics were comparable to the demographic characteristics and lifetime cigarette use prevalence rates of all middle schools/junior high schools in Kansas City: 50.7 percent male; 76.6 percent white, 19.2 percent black, and 4.2 percent other races; and 53.4 percent reporting lifetime use. Of the 1,607 students measured at baseline, 3.1 percent dropped out of the study (i.e., they had no further measurement after baseline); 91 percent had data that merged between baseline and six months; 84 percent had data that merged between baseline and one year; 78 percent had data that merged between baseline and two years; and 70 percent $(n=1,122)$ had data that merged across all waves of measurement.

\section{Intervention methods}

The Midwestern Prevention Project expands over a six-year period to include school, media, parent, community organization, and health policy programs that focus on resistance skills training and environmental support for nonsmoking and non-drug use norms. The components are introduced into communities at the rate of approximately one per year, in sequence, beginning with the most proximal educational influences on youth (school and parents) to the more distal (community organizations and policy change), with mass 

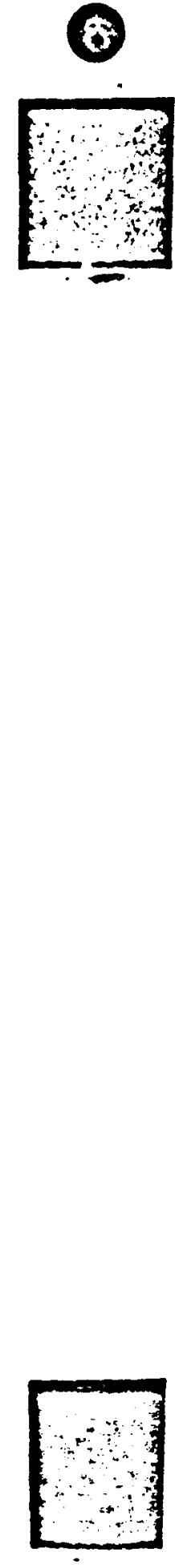

media used throughout all years to introduce, promote, and reinforce the other components (17). From 1984 to 1986, the program in Kansas City communities consisted of a 10-session school program for resistance skills training and homework sessions with parents, a five-session booster school program and homework, a parent training and organization program, and media coverage of the project. The four components focused on resisting peer pressure to smoke and use drugs, preparing for the pressures involved in the transition to high school, counteracting prosmoking modeling influences by adults, media, and the environment, and promoting positive parentchild communication about drug prevention practice $(5,12)$.

The school program and booster sessions were delivered in classrooms in health, science, or social studies courses, were 45-50 minutes in duration each, and were conducted by teachers using behavioral demonstration, role-playing, group discussion, and peer facilitation $(11,13)$. Teachers were trained by project health educator staff in an initial three-day workshop and a oneday refresher workshop. The workshops included an overview of theory, scheduling, and demonstration and practice of sessions and delivery methods. The parent program consisted of 3-6 organizational meetings per year, support activities for the school, and an educational seminar for all parents. Training for the parent program consisted of a one-day workshop each year for principals, parent group representatives, and student leaders. Training focused on changing school policy regarding prevention education, initiating smoking and alcohol controls in and around schools, and implementing seminars for ali parents on parent-child communication and prevention support skills. A total of 12 teachers, 32 parents, eight principals, and 16 student leaders were trained to deliver school or parent program components in the panel schools. Mass media programming consisted of 1- to 2-minute news clips of training and program implementation aired on the 5 p.m. and 6 p.m. news by the three major network stations, television and radio talk shows with project staff, and a televised press conference. A total of 14 television, 15 radio, and 41 print media promotions for the project were broadcast or distributed over the entire Kansas City Metropolitan Area from 1984 to 1986, including the control group areas.

Four methods were used to maximize the quality of subsequent program implementation (23). First, Kansas City-based research staff served as resource personnel to teachers and parent groups through periodic phone calls and meetings with principals (24). Second, a project archivist observed and rated an average of two school program sessions and two parent group meetings per year. Third, session-bysession program implementation data were collected by University of Southern California staff from teachers (in self-report surveys) and parent group members (in telephone survey interviews). Fourth, three members of the Kansas City-based staff developed a five-point consensus rating of overall program implementation quality (1 $=$ very high; $5=$ very poor). Each of the four methods was implemented independently of the others. Data collected by these methods were used to provide feedback to program implementors and to annually revise training and program materials. Analysis of summary implementation scores indicated that the program was implemented as designed and that implementation was not related to baseline smoking rates at each school.

\section{Measurements}

Student survey. Students in program and control schools completed a self-administered questionnaire approximately one and one half months prior to the intervention between early November 1984 and early January 1985 , and again at six months, one year, and two years. The questionnaire was developed from prior research (25) and included a battery of items measuring smok- 
ing and drug use and social psychologic factors related to drug use.

Four items were used as indicators of program effect in this study: use of cigarettes in a lifetime, last month, or last week, and current use of cigarettes, which subsumed the other three frequencies of use. The items were scaled ordinally, with six or eight response categories per item representing increasing amount of severity. To evaluate whether the program affected prevalence rates, we rescaled lifetime, monthly, and weekly smoking items to dichotomous categories $(0=$ no use, $1=$ ever use in a lifetime, in the last month, or in the last week). To evaluate whether the program affected levels of use differentially, we used all the categories of the "current

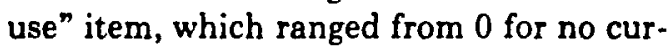
rent use to 6 for one half pack or more per day. Internal consistency and test-retest reliability of these items are moderately high (Cronbach's alpha $=0.82-0.86$; threeweek test-retest reliability of individual items $=0.41-0.90(25))$. The one-year testretest correlation $(r)$ calculated on the lifetime cigarette use item was $0.80(p<$ 0.0001 ).

Four demographic items were used as independent variables on the basis of research suggesting that there may be differences in smoking between schools: urbanicity, coded as rural, suburban, suburban/ urban, or urban; socioeconomic status, coded as percentage of fathers in professional occupations on the basis of 1980 US census designations; race, coded as percent white; and grade (six or seven) $(6,15,26)$.

Biochemical measure of smoking. Immediately prior to self-report questionnaire administration, a sample of expired air was obtained and the concentration of carbon monoxide was estimated as a measure of cigarette smoking, using the MiniCO Indicator (Catalyst Research Corporation, Owings Mills, MD) (27). The instrument was calibrated each day of data collection prior to actual use on students, to adjust for ambient air levels of carbon monoxide produced by heating systems and other sources. Each student was instructed to inhale deeply, hold his/her breath for 10 seconds, and then exhale through a straw to blow up the balloon attached to the Indicator. Indicator readings were recorded by a data collector. Consistent with procedures in other recent smoking prevention research, the carbon monoxide measure was used to increase the accuracy of selfreported smoking data (27).

\section{Data analysis}

An unconditional logistic equation model was used to estimate program effects on smoking prevalence rates. The primary analysis of program effects on prevalence rates was conducted using school as the unit of analysis to match the unit of assignment with all subjects present at each wave of measurement (28). Analyses were then replicated using the individual as the unit of analysis, first on all persons present at each wave to match the sample sizes used in the school-as-unit analysis ( $n$ at each wave ranged from 1,259 to 1,680 ) and again only on persons who were present at all four waves, who had no missing data, and whose eight-digit identification code could be merged across all waves $(n=1,122$ or 70 percent of the baseline sample). The model was specified in the form of a multivariate regression estimated by least squares. The logits of the proportions of lifetime, monthly, and weekly cigarette smokers served as the dependent variables, to adjust for abnormal distributions of smoking prevalence. Zero probabilities were replaced by $0.5 \times 326$, where 326 was the size of the largest grade cohort in a school. In addition, a cross-sectional ordinal logistic model was used to estimate whether program effects were homogenous across different levels of use with the individual as the unit of analysis (29).

Grade $(0=$ sixth grade, $1=$ seventh grade), urbanicity $(0=$ rural, $1=$ suburban, $2=$ suburban/urban, $3=$ urban), socioeconomic status (percentage of fathers in professional occupations), and race (per- 


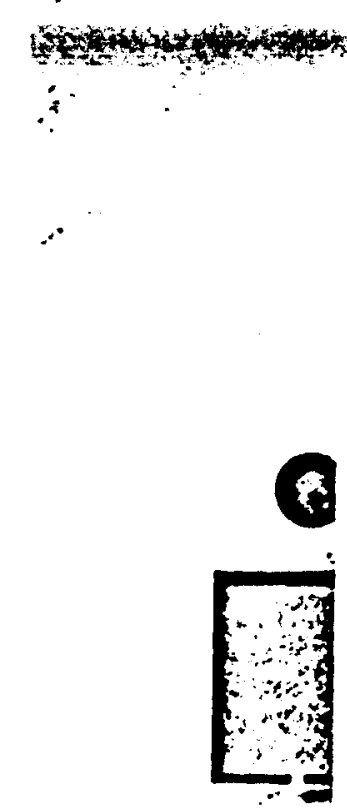

cent white) were explored as first step independent variables to control for developmental, geographic, and racial differences in smoking across schools. Urbanicity and socioeconomic status were highly correlated with race ( $r=0.87$ and 0.75 , respectively; $p<0.001$ ). To focus on demographic variables most immediately relevant to school prevention program planning and to reduce the potential for multicollinearity of demographic variables, we retained only grade and race in subsequent analyses. In replication analyses using the individual as the unit, sex was controlled for, as well as grade and race. Analyses were conducted using Statistical Analysis System (30) programs for multivariate regression (REG) and ordinal logistic regression (CATMOD).

\section{RESULTS}

\section{Equivalence of study groups}

To determine the equivalence of the study groups at baseline, we tested for differences between proportions for demographic characteristics and smoking prevalence rates, adjusting for grade (table 1). Although there were more white students and fewer minority students in program schools compared with control schools, there were no significant differences for any smoking variable. There were also no significant group differences within each grade, with one exception: Among sixth grade students, there were more lifetime smokers in the control group than in the program group at baseline, using unadjusted data and the individual as the unit of analysis $(p<0.006)$. The proportion of students absent or lost to subsequent evaluation also did not differ significantly between program schools and control schools $(p>0.15)$. To evaluate the smoking characteristics of individual dropouts, we compared students who were present at baseline and at all subsequent evaluations with students who were present at baseline but absent for one or more subsequent evaluations, in program and control groups (table $2(20))$. The individual was the unit of
TABLE 1

Demographic characteristics and smoking rates among sixth and seventh graders from eight schools in the Kansas City Standard Metropolitan Statistical Area at baseline, Midwestern Prevention Project, fall 1984†

\begin{tabular}{ccc}
\hline & Program \\
group & Control \\
$(n=904)$ & $(n=703)$ \\
$(\%)$ & $(\%)$ \\
& & $(\%)$ \\
\hline
\end{tabular}

Sex

$\begin{array}{lll}\text { Female } & 48.8 & 48.6\end{array}$

Race

White

Black

$88.8 \quad 78.2^{*}$

Other

$9.7 \quad 18.5^{*}$

$4.5 \quad 3.3$

Smoking prevalence rate

$\begin{array}{lll}\text { Lifetime use } & 45.2 & 52.0\end{array}$

Last month use $\quad 11.5 \quad 9.7$

$\begin{array}{lll}\text { Last week use } & 6.2 & 4.4\end{array}$

* $p<0.05$ (one-tailed tests).

+ Percentages are adjusted for grade only. Within the sixth grade, unadjusted baseline smoking prevalence rates were $39.8 \%, 11.4 \%$, and $7.0 \%$ for lifetime, last-month, and last-week use in program schools and $53.6 \%, 10.4 \%$, and $4.8 \%$, respectively, in control schools. Within the seventh grade, unadjusted rates were $51.1 \%, 12.5 \%$, and $5.6 \%$ for lifetime, last-month, and last-week use in program schools and $52.6 \%, 9.9 \%$, and $4.3 \%$, respectively, in control schools. School is the unit of analysis.

analysis. Results of log linear analyses on attrition $\times$ user interactions indicated that students who left the study were more likely to be cigarette smokers than students who were present for one or more waves of measurement after baseline ( $p$ 's $<0.05-0.001$ ). However, there were no significant differences between program and control groups in the proportion of smokers who were absent at any wave or who dropped out of the study ( $p$ 's $>0.20$ ).

\section{Program effects on smoking prevalence rates}

Figure 1 shows changes in prevalence rates for recent smoking among program (intervention) and control (nonintervention) schools across each wave, adjusted for race and grade. As the data indicate, there was a significant effect of program on cigarette smoking. At baseline, program schools showed a slightly higher proportion 
TABLE 2

Baseline pencentage of smokers in each group evaluated at all four waves of measurement compared with smokers absent at one, two, or three waves of measurement, Miduestern Preuention Project, 1984-1986*

\begin{tabular}{|c|c|c|c|c|c|c|}
\hline \multirow{2}{*}{ Cigarette use } & \multicolumn{2}{|c|}{$\begin{array}{c}\text { Evaluated at all four } \\
\text { woves } \\
(n=1,122)\end{array}$} & \multicolumn{2}{|c|}{$\begin{array}{c}\text { Absent at one or two } \\
\text { waves } \\
(n=435)\end{array}$} & \multicolumn{2}{|c|}{$\begin{array}{l}\text { Absent at three waves } \\
\qquad(n=50)\end{array}$} \\
\hline & $\begin{array}{l}\text { Program } \\
\text { group }\end{array}$ & $\begin{array}{l}\text { Control } \\
\text { group }\end{array}$ & $\begin{array}{l}\text { Program } \\
\text { group }\end{array}$ & $\begin{array}{l}\text { Control } \\
\text { group }\end{array}$ & $\begin{array}{l}\text { Program } \\
\text { group }\end{array}$ & $\begin{array}{l}\text { Control } \\
\text { group }\end{array}$ \\
\hline Lifetime & 47.5 & 40.5 & 50.7 & 61.7 & 64.3 & 77.3 \\
\hline Last month & 10.5 & 7.9 & 14.0 & 14.0 & 25.0 & 13.6 \\
\hline Last week & 5.2 & 3.2 & 10.0 & 6.5 & 10.7 & 9.1 \\
\hline
\end{tabular}

- The number of smokers who dropped out of the control group versus the number of smokers who dropped out of the program group was not significantly different at any level of use (all $p$ 's $>0.20$ ). Data are unadjusted. The individual is the unit of analysis.

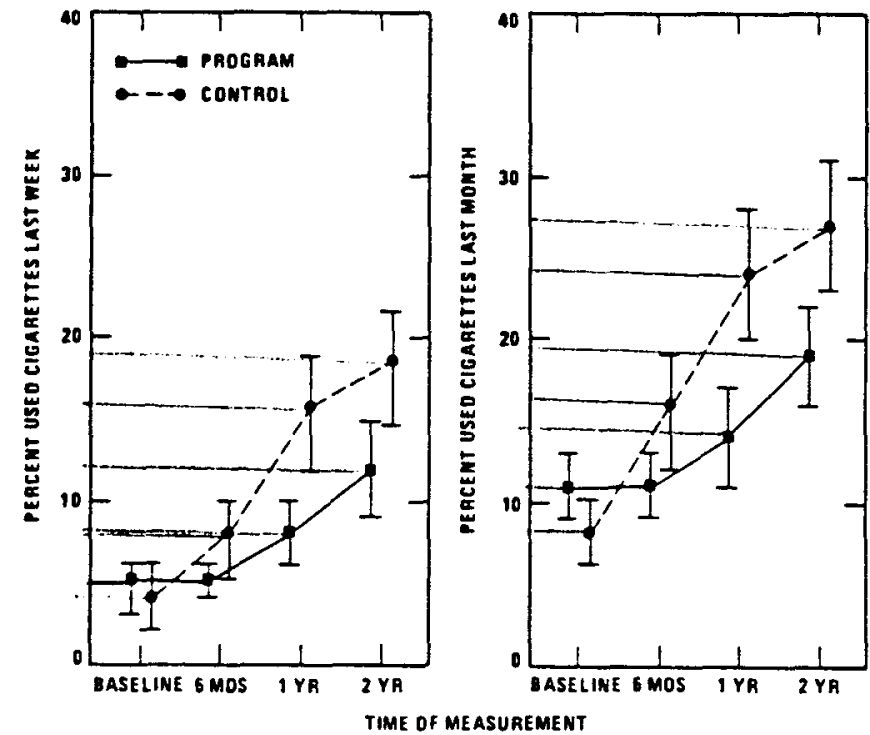

Figure 1. Changes in prevalence rates of smoking (percent of smokers) in the last week and in the last month in program and control schools, from baseline through two years, Midwestern Prevention Project, 19841986. Data are adjusted for race and grade; school is the unit of analysis. Bars, standard error.

of persons who had used cigarettes in the last month and in the last week than did control schools, but program schools showed a lower proportion of cigarette users six months after program implementation. This pattern was maintained throughout the next two years. The pattern for lifetime cigarette use was similar, with the exception that the program effect did not occur until two years after baseline (figure 2; data adjusted for race and grade).

Results of the unconditional regression analyses are presented in table 3 . Longitudinal program effects were calculated by subtracting baseline from six-month, oneyear, and two-year intervention parameter estimates, with grade and race entered as control variables. Parameter estimates were then transformed to odds ratios. Race and grade were marginally significant correlates of smoking at most waves. Schools with higher percentages of white students tended to have fewer cigarette users than schools with higher percentages of minority students; junior high schools had more cigarette users than middle schools. At all waves of measurement after baseline, the program effect on recent smoking was sig- 
nificant; at two years, the program effect on lifetime smoking was also marginally significant. At two years, students in program schools were 0.74 times as likely as students in control schools to have tried cigarettes at least once in their lifetimes, 0.58 times as likely to have smoked in the last month, and 0.61 times as likely to have smoked in the last week. Separate regression analyses were also conducted on school-level data, stratifying by grade and by race (white vs. nonwhite students, each aggregated at the school level). Results indicated significant program effects within each grade and racial category ( $p$ 's ranged from $<0.05$ to 0.001 ). Results were also replicated with the individual as the unit of analysis, both on all students present at each wave and on students present at all four waves.

Table 4 presents the net decrease in smoking prevalence rates produced in the program schools compared with the control schools after each year of intervention. The observed mean percentage difference summarizes the trends represented in figure 1. The observed and adjusted net differences

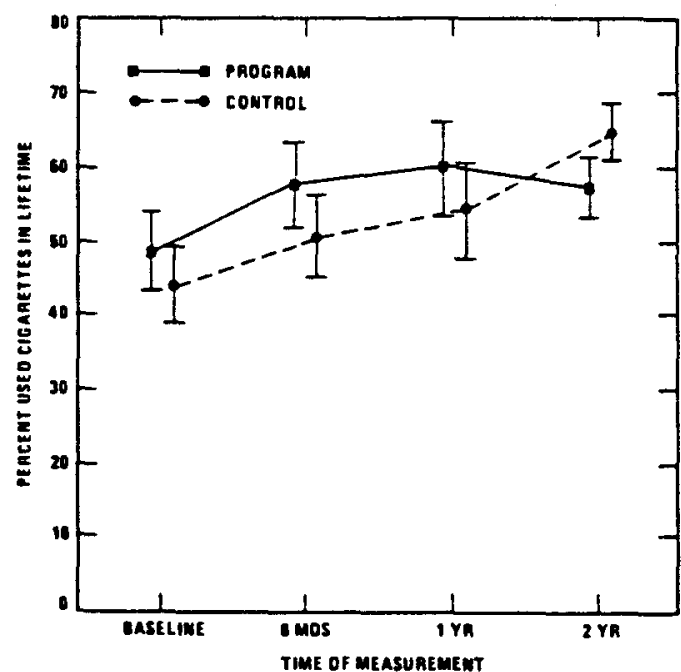

FIGURE 2. Changes in prevalence rates of smoking (percent of smokers) in lifetime (ever smoked) in program and control schools, from baseline through two years, Midwestern Prevention Project, 1984-1986. Data are adjusted for race and grade; school is the unit of analysis. Bars, standard error.

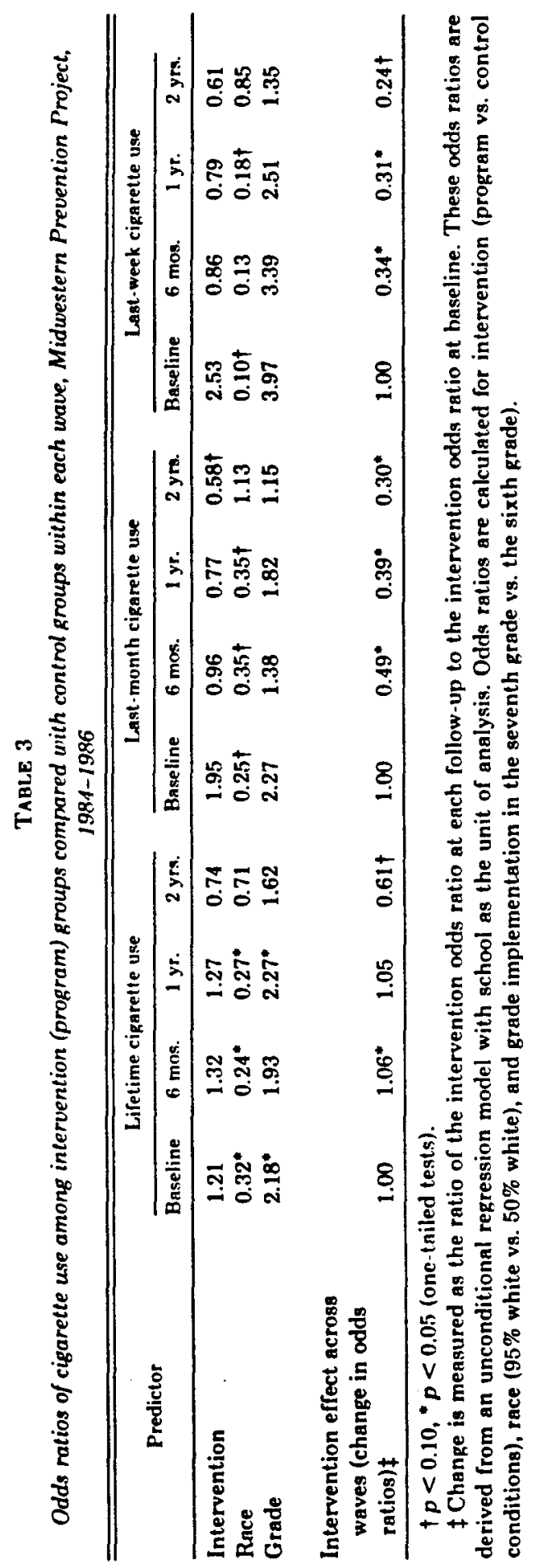


TABLE 4

Unadjusted and adjusted net differences in the percentage of smokers between program and control graups from baseline to each follow-up wave, Midwestern Prevention Project, 1984-1986

\begin{tabular}{|c|c|c|c|c|c|c|}
\hline \multirow{2}{*}{ Smoking variable } & \multicolumn{3}{|c|}{ Unsdjusted net difference } & \multicolumn{3}{|c|}{ Adjusted net difference } \\
\hline & 6 months & 1 year & 2 years & 6 months & 1 year & 2 years \\
\hline Lifetime use & 2.3 & 0.0 & -5.0 & 2.3 & 1.2 & $-11.7+$ \\
\hline Last-month use & $-5.9^{*}$ & $-10.1 \cdots$ & $-12.5^{*}$ & $-7.5^{*}$ & $-10.2^{* *}$ & $-16.0^{* *}$ \\
\hline Last-week use & $-5.5^{* *}$ & $-8.4^{\omega *}$ & $-10.3^{* *}$ & $-6.4^{*}$ & $-7.9^{\star}$ & $-11.7^{* *}$ \\
\hline
\end{tabular}

$\dagger p<0.10,{ }^{*} p<0.05,{ }^{* *} p<0.0$ ! (one-tailed tests).

$\ddagger$ Analyses are based on an unconditional model with school as the unit, adjusted for race and grade.

indicate that the strength of the program effect increased slightly when grade and race were controlled for in analyses. With no adjustment for demographic variables, program schools after two years had approximately 13 percent fewer cigarette users in the last month than would be expected. The 13 percent net decrease in smoking in program schools translates to a 30 percent rate of decline in program schools relative to control schools $(p<$ 0.04). Expired air samples were analyzed for carbon monoxide at two years, when students were in the eighth or ninth grade. Carbon monoxide levels were correlated $r$ $=0.26(p<0.0001)$ with self-reported smoking, averaged across all schools, both grades, and all levels of smoking in the last week, including no use in the last week. There were no significant differences between experimental groups in the size of the correlations $(r=0.30$ in program schools and $r=0.25$ in control schools; $Z$ $=1.08$ ). The low values of the correlations probably reflect the unreliability of the carbon monoxide measure for detecting infrequent smoking levels (27) but are consistent with program effects on self-reported smoking.

\section{Program effects on levels of smoking}

Ordinal logistic regression analyses tested the effect of the program at each wave cross-sectionally across six levels of current use, from no current use through heavy smoking of one half pack or more per day. The program effect across all levels of current use was not significant at six months but did achieve significance at one year and at two years $\left(\chi^{2}(3)=20.01, p<\right.$ 0.01 , and $\chi^{2}{ }_{(5)}=11.09, p<0.05$, respectively). The magnitude of the effect did not differ significantly across levels of use, indicating that the program was similarly effective for all categories of current smoking.

\section{Discussion}

Results of the Midwestern Prevention Project across the first two years appear promising. The low rate of increase in smoking onset in a population-based sample of students in program schools, contrasted with a sharp increase in smoking onset among students in control schools, suggests that the project may be significantly reducing risk for subsequent cardiovascular disease and lung cancer by delaying the onset of cigarette smoking $(31,32)$. The magnitude of the effects of the combined school, parent, and media program components on both smoking prevalence rates and levels of smoking appears to be greater than that of recent school smoking prevention programs (12), and the effects seem to appear earlier than the effects of multicomponent community programs for heart disease prevention $(21,22)$. Maintenance of the 30 percent fewer monthly smokers in program schools relative to control schools throughout midadulthood could result in significent decreases in mortality, morbidity, and public health costs associated with treatment, insurance, and work days lost due to heart disease and lung disease (33). Even if program effects 

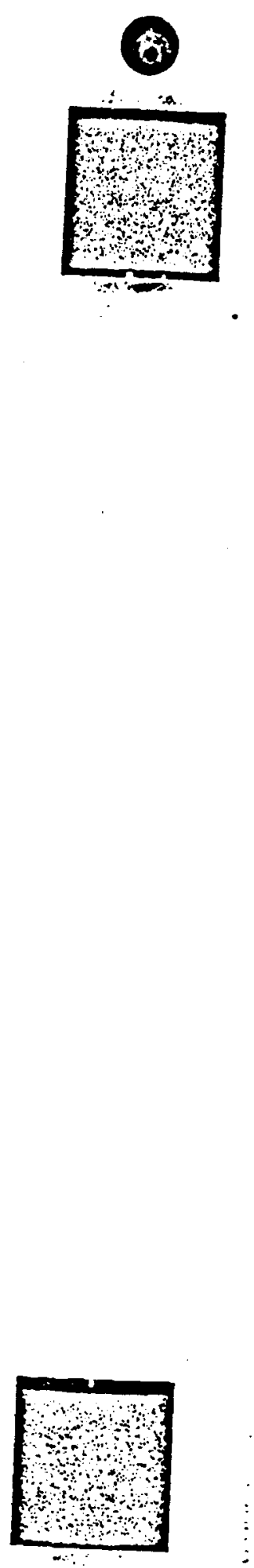

decay by one half, the impact on smokingrelated mortality and morbidity rates would still be significant from both a public health and a clinical standpoint (33). However, public health projections assume "true" and stable program effects. Alternative explanations for the presumed effects must be considered, including nonequivalence of groups because of school selection biases (nonrandom selection) or attrition, and social desirability response bias.

The lack of significant baseline differences between program and control schools which might have indicated that assignment was based on more need for prevention or on a greater smoking problem in program schools mitigates a nonequivalence interpretation of the findings. Differential attrition in program schools and control schools, which could relate to baseline differences in smoking and school selection bias, also did not occur. However, it is possible that a self-selection bias of individuals rather than schools could have affected results. If we assumed that students who were present at all waves of measurement represented persons who were at low risk for smoking and who had families that participated more compared with students who were not present at all waves, then we could conclude that program effects might have been confounded by different levels of smoking risk and different levels of program exposure. Although analyses have not yet been conducted on family level participation in program components, preliminary analyses of parent reports of family member smoking, disapproval of adolescent smoking, and importance of personal involvement in smoking prevention programs have indicated no significant differences between program or control groups at baseline and no significant differences between persons present at all waves and persons present at some waves in each group. In addition, the outcomes of individual-level analyses using all students versus only those students present at all waves were similar, and both were comparable to analyses using school as the unit.
The potential for social desirability response bias, which could have been produced by subject association of a program with testing activities (measurement $x$ treatment interaction), was minimized by conducting testing approximately one and one half months prior to and after program implementation, with independent data collectors who were blind to experimental conditions. In addition, the variability in the timing and direction of program effects on monthly and weekly smoking compared with lifetime smoking does not support a response bias interpretation of the findings. Finally, the significant positive correlations found between the self-report measure of smoking and the carbon monoxide measure suggests that the self-report measure is a valid measure of smoking ( $\hat{\beta}$ for the program effect $=0.080$ (standard error $=$ 0.009 ), $p<0.0001$, which represents a 0.08 increase in parts per million (ppm) of carbon monoxide per self-reported cigarette increase in the last week; mean $=1.78$ ppm). Some studies operating under more controlled field or laboratory test conditions have yielded higher correlations than the 0.26 average correlation reported here. (The average correlation between self-reported number of cigarettes smoked in the last week and carbon monoxide in students aged 11-13 years has been reported as $r=$ 0.39 under controlled classroom data collection procedures involving measurement of both carbon monoxide and salivary thiocyanate and analysis of carbon monoxide levels outside of the classroom (27).) However, the self-reported smoking prevalence rates obtained in this panel study at baseline were similar to those from other recent studies conducted under various experi. mental conditions and in different geographic areas $(8,11,15)$. The similarit: suggests that the results of this study ari reliable and likely to be generalizable to school-attending youth in other US com munities.

The pattern of results obtained thus fas and comparison of these results with othe prevention studies that have used simila 
self-report measures, suggests that a selfreport response bias is not operating in this study. However, this alternative explanation of program effects will continue to be explored as adolescents increase in age, when increases in the percentage of daily smokers should enable more reliable biochemical detection of smoking (27). (Preliminary analyses of three-year data indicate that the correlation between carbon monoxide and self-reported smoking in the last week is $r=0.56(r=0.57$ in program schools and $r=0.55$ in control schools, $p<$ 0.0001).)

Future research should explore environmental factors that may impact on smoking and smoking prevention. The finding of fewer cigarette users in primarily white schools might be used to generate and test hypotheses about health behaviors and norms that are promoted among different racial/ethnic populations. Supplementary analyses stratifying white and nonwhite students, using the individual as the unit of analysis, showed program effects on both subgroups; results were similar when school was used as the unit of analysis and when population subgroup differences were evaluated as a program $\times$ race interaction. However, recent research suggests that white, upper socioeconomic level schools may promote a smoke-free environment more than other schools (34). Studies could be developed to evaluate indicators of social support for not smoking, including faculty and student smoking policies, emphasis given to cigarette smoking in health education curricula at the school level, and public no-smoking ordinances at the community level. In addition, the relative social climates for smoking, drinking, and marijuana use could be explored, in terms of perceived use by others. Preliminary analyses of estimated peer and adult use of each substance and number of parties attended have shown no differences between experimental groups at baseline.

In summary, the interim results of the Midwestern Prevention Project showed significant reductions in smoking after six months, with increased effects after one year and after two years. These program effects have appeared somewhat earlier and more strongly than effects reported from several school-based programs (12) and from school program components of larger community efforts $(21,22)$. This suggests that a population-based program that involves parents and community mass media support in addition to school programming may represent a more powerful deterrent to smoking than school programming alone. In the long term, multicomponent programs also may have a greater public health impact on mortality and morbidity related to chronic diseases of lifestyle. Program effects do not appear to be confounded by alternative methodological or theoretical explanations.

Students in this panel study are being followed longitudinally for six years to determine maintenance and possible enhancement of effects as more program components are added to the Midwestern Prevention Project. New methodologies for evaluating and interpreting the longitudinal effects of primary prevention programs based on Midwestern Prevention Project data have been reported in another paper (35).

\section{REFERENCES}

1. Ravenholt RT. Addiction morality in the United States, 1980: tobacco, alcohol, and other substances. Popul Dev Rev 1983;310:697-724.

2. US Public Health Service. The health consequences of smoking: cancer. A report of the Surgeon General. Washington, DC: US Department of Health and Human Services, 1982. (DHHS publication no. (PHS)82-50179).

3. US Public Health Service. The health consequences of smoking for cardiovascular disease: a report of the Surgeon General. Washington, DC: US Department of Health and Human Services, 1983. (DHHS publication no. (PHS)84-50274).

4. Fraumeni J, Miller AB, Hirayama T, et al. Smoking and cancer in the United States. Prev Med 1980:9:169-73.

5. Killen JD. Prevention of adolescent tobacco smoking. the social pressure resistance training approach. J Child Psychol Psychiatry 1985;26:715.

6. Baugh JG, Hunter SM, Webber LS, et al. Devel. opmental trends of first cigarette smoking experience of children: The Bogalusa Heart Study. Am J Public Health 1982;72:1161-4. 
7. Jessor R. Problem behavior and developmental transition in adolescence. J Sch Health 1982;52: 295-300.

8. Pentz MA. Social skills and self-efficacy in adolescent drug abuse prevention. In: Wills TA, Shiffman S, eds. Coping and substance use. New York: Academic Press, 1985:117-42.

9. Luepker RV, Johnson CA, Murray DM, et al. Prevention of cigarette smoking: three-year follow-up of an education program for youth. $\mathrm{J} \mathrm{Be}$ hav Med 1983;6:53-62.

10. Tobler NS. Meta-analyses of 143 adolescent drug prevention programs: quantitative outcome results of program participants compared to a control or comparison group. J Drug Issues 1986;17: 537-67.

11. Schinke SP, Gilchrist LD, Snow WH. Skills in tervention to prevent cigarette smoking among adolescents. Am J Public Health 1985;75:665-7.

12. Flay BR. Psychosocial approaches to smoking prevention: a review of findings. Health Psychol 1984;4:449-88.

13. Connell DB, Turner RR, Mason EF. Summary of findings of the School Health Education Evaluation: health promotion effectiveness, implemen. tation, and costs. J Sch Health 1975;55:316-21.

14. Bartiett EE. The contribution of school health education to community health promotion: What can we reasonably expect? Am J Public Health 1981;71:1384-91.

15. Murray DM, Davis-Hearn M, Goldman Al, et al. Four and five year follow-up results from four seventh-grade smoking prevention strategies. J Behav Med 1988;11:396-405.

16. Battjes RJ. Prevention of adolescent drug abuse. Int $\mathrm{J}$ Addict 1985;20:1113-34.

17. Johnson CA, Hansen WB, Pentz MA. Comprehensive community drug abuse prevention. $\mathrm{J}$ Children Contemp Soc 1986;18:181-99.

18. Cook TD. Priorities in research on smoking prevention. In: Bell $C$, Battjes $R$, eds. Prevention research: deterring drug abuse among children and adolescents. Nat Inst Drug Abuse Res Monogr Ser 1986;63:196-220.

19. Flay BR, Best JA. Overcoming design problems in evaluating health behavior programs. Eval Health Professions 1982;5:43-69.

20. Hansen WB, Collins LM, Malotte CK, et al. At trition in prevention research. J Behav Med 1985;8:261-75.

21. Puska $P$, Vartiainen E, Pallonen $U$, et al. The North Karelia Youth Project: evaluation of two years of intervention study on health behavior and CVD risk factors among 13- to 15-year-old children. Prev Med 1982;11:550-70.

22. Perry CL, Klepp KI, Schulz JM. Primary prevention of cardiovascular disease: community-wide strategies for youth. J Consult Clin Psychol 1988;56:358-64.

23. Mark MM. Treatment implementation, statistica] power, and internal validity. Eval Rev 1983;7: 543-9.

24. Pentz MA, Cormack C, Flay B, et al. Balancing program and research integrity in community drug abuse prevention: Project STAR approach. J Sch Health 1986;56:389-93.

25. Graham JW, Flay BR, Johnson CA, et al. Relia. bility of self-report measures of drug use in prevention research: evaluation of the Project SMART questionnaire via the test-retest reliability matrix. Drug Educ 1984;14:175-93.

26. Graham JW, Flay BR, Johnson CA, et al. Group comparability: a multiattribute utility approach to the use of random assignment with small numbers of aggregated units. Eval Rev 1984;8:247-60.

27. Pechacek T, Murray DM, Luepker RV, et al. Measurement of adolescent smoking behavior: rationale and methods. J Behav Med 1984;7:123-40.

28. Dwyer JH. Statistical models for the social and behavioral sciences. New York: Oxford University Press, 1983.

29. Agresti A. A survey of strategies for modeling cross-classifications having ordinal variables. J Am Stat Assoc 1983;78:184-98.

30. SAS Institute Inc. SAS user's guide: statistics, version 5 ed. Raleigh, NC: SAS Institute, Inc., 1985.

31. Hunter SM, Croft JB, Parker FC. Biobehavioral studies in cardiovascular risk development. In: Berenson GS, ed. Causation of cardiovascular risk factors in children: perspectives on cardiovascular risk in early life. New York: Raven Press, 1985:223-53.

32. Walter HJ, Hofman A, Connelly PA, et al. Primary prevention of chronic disease in childhood: changes in risk factors after one year of intervention. Am J Epidemiol 1985;122:772-81.

33. Green LW, Wilson RW, Bauer KG. Data requirements to measure progress on the objectives for the nation in heaith promotion and disease prevention. Am J Public Health 1983;73:18-24.

34. Cleary PD, Hitchcock JL, Semmer N, et al. Adolescent smoking: research and health policy. Smoking and Policy, Harvard University. Milbank Q 1986:137-71.

35. Dwyer JH, Mackinnon DP, Pentz MA, et al. Estimating intervention effects in longitudinal studies. Am J Epidemiol 1989:130:781-95.

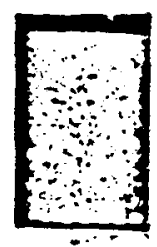

